\title{
Cidadania nas organizações empresariais: provocando reflexões sobre respeito à diversidade ${ }^{1}$
}

\author{
Citizenship in business organizations: reflections about the respect for diversity \\ Ciudadanía en organizaciones empresariales: reflexiones sobre el respecto a la diversidad
}

DOI: https://doi.org/10.1590/1809-58442021215

\section{Cicilia Maria Krohling Peruzzo ${ }^{1}$}

https://orcid.org/0000-0002-6384-8848

${ }^{1}$ (Universidade do Estado do Rio de Janeiro, Faculdade de Comunicação Social, Programa de Pós-Graduação em Comunicação Social. Rio de Janeiro - RJ, Brasil).

\section{Resumo}

Este texto discute a discriminação social nas organizações. O objetivo é refletir sobre conceitos que embasam a compreensão da relação entre direitos humanos e de cidadania para melhor entender a questão do respeito à diversidade nas organizações como algo mais complexo do que o oportunismo para aumentar a lucratividade. Baseia-se em pesquisa bibliográfica e documental numa abordagem preliminar, portanto, sem a pretensão de esgotar a problemática. Conclui-se que a cidadania pode ser mais bem compreendida se tomada na perspectiva da dupla intersecção entre os direitos civis e os direitos cívicos. Os direitos cívicos remetem a um sentido universalizante dos direitos da pessoa, de um povo e da própria espécie humana.

Palavras-chave: Cidadania. Organizações empresariais. Discriminação. Igualdade.

\begin{abstract}
This article discusses social discrimination in organizations. The objective is to reflect on the concepts that support the understanding of the relationship between human rights and citizenship to better comprehend the issue of respect for diversity in organizations as something more complex than the opportunism to increase profitability. It is based on bibliographical and documentary research as a preliminary approach, therefore without the pretension of exhausting the problematic. It concludes that citizenship can be better understood if regarded in the perspective of the double intersection between civil rights and civic rights. Civic rights refer to a universal sense of the rights of the person, of a people and of the human species itself.
\end{abstract}

Keywords: Citizenship. Business Organizations. Discrimination; Iguality

1 Versão reelaborada do texto intitulado "Igualdade e direitos humanos nas organizações empresariais e cidadania" publicado no livro "Comunicação, diversidades e organizações: pensamento e ação", organizado por Else Lemos e Patricia Salvatori (São Paulo: Editora Abrabcorp, 2019. p. 25-45). 


\section{Resumén}

Este texto discute la discriminación social en las organizaciones. El objetivo es reflexionar sobre los conceptos que ayudan la comprensión de la relación entre derechos humanos y de ciudadanía para mejor entender la cuestión de lo respecto a l diversidad em las organizaciones como algo más complejo do que el oportunismo para aumentar la lucratividad. El estudio es basado en investigación bibliográfica y documental en abordaje preliminar, por lo tanto, si la pretensión de agotar la problemática. La conclusión es que la ciudadanía pode ser más bien comprendida si tomada en la perspectiva de la doble intersección entre los derechos civiles y los derechos cívicos. Lo derechos cívicos remiten a uno sentido universalizante de los derechos de la persona, derechos de una nación y de la propia especie humana.

Palabras clave: Ciudadanía. Discriminación. Organizaciones empresariales. Igualdad.

\section{Introdução}

Este texto discute o tema da discriminação humana nas organizações, no tocante a não absorção equitativa de mão-de-obra de mulheres, negros e pessoas com deficiência, além de refletir sobre a limitação de políticas empresariais ditas inclusivas quando tomadas somente pelo ângulo da vantagem competitiva. A abordagem é tecida em quatro tópicos: breves palavras sobre cidadania, relação entre direitos humanos e direitos de cidadania, o discurso das organizações sobre diversidade, e visões de diversidade e meritocracia.

São feitas pontuações no intuito de provocar reflexões dos profissionais, especialmente de relações públicas e de comunicação organizacional, ao pautarem as estratégias programáticas do exercício profissional, sejam elas diretamente no mercado industrial e de serviços ou no ensino de graduação e pós-graduação no campo da Comunicação Social. O objetivo é refletir sobre a relação entre direitos humanos e de cidadania para melhor entender a questão do respeito à diversidade nas organizações como algo mais complexo do que o oportunismo para aumentar a lucratividade. Baseia-se em pesquisa bibliográfica e documental numa abordagem ensaística preliminar, portanto, sem a pretensão de esgotar a problemática.

\section{Palavras sobre cidadania}

Cidadania é uma palavra que carrega uma densidade de conceitos, embora seja usada quase como palavra de ordem nos discursos sobre participação social e política nas sociedades democráticas. Diante do limite de espaço para se aprofundar os conceitos e sua evolução histórica (PINSKY; BASSANEZI PINSKY, 2003, BOBBIO, 1991, KROHLING, 2009), opta-se em situar algumas de suas ideias-força como forma de contextualizar o tema. Entre elas, estão os princípios igualdade e liberdade. São princípios fundamentais universalmente aceitos como base da cidadania e assegurados pela Constituição Brasileira de 1988, que, em seu artigo 5º explicita: “Todos são iguais perante a lei, sem distinção de qualquer natureza, garantindo-se aos brasileiros e aos estrangeiros residentes no País 
a inviolabilidade do direito à vida, à liberdade, à igualdade, à segurança e à propriedade” (CONSTITUIÇÃO, 2016, p. 13).

Ser cidadã/cidadão é poder exercer e usufruir desses princípios como direitos. Nas palavras de Pinsky (2003, p. 9),

ser cidadão é ter direito à vida, à liberdade, à propriedade, à igualdade perante a lei: é em resumo ter direitos civis. É também participar dos destinos da sociedade, votar, ser votado, ter direitos políticos. Os direitos civis e políticos não asseguram a democracia sem os direitos sociais, aqueles que garantem a participação dos indivíduos na riqueza coletiva: o direito à educação, ao trabalho, ao salário justo, à saúde, a uma velhice tranquila. Exercer a cidadania plena é ter direitos civis, políticos e sociais.

Assim sendo, ser cidadã/cidadão é ter o direito de participar como sujeito ativo da feitura da sociedade e de poder compartilhar das benesses do desenvolvimento histórico, usufruir da riqueza gerada socialmente, inclusive, do respeito aos valores consagrados à dignidade humana, com igualdade e liberdade, portanto, independentemente de classe social, condição de gênero, etnia, características físicas, procedência e assim por diante. Cidadania também remete à participação.

Na realidade brasileira concreta, a desigualdade é gritante em todas essas dimensões. E a liberdade é cerceada de diferentes maneiras. Pobres, negros, indígenas, mulheres, homossexuais, nordestinos etc. são discriminados, apesar da existência de leis protetoras.

Nesse ambiente, surgem as lutas sociais para ampliar o reconhecimento social e jurídico dos direitos. Por quê? Porque os direitos da pessoa humana precedem os direitos legais - ou de cidadania, ou seja, os direitos humanos reconhecidos pelo Estado. Os direitos humanos são inerentes à pessoa. São universais e históricos e extrapolam os limites de uma nação. Por exemplo, o direito de morar dignamente, o direito à vida ou o direito ao trabalho, independentemente de cor da pele, procedência, peso, idade.... Na evolução histórica do reconhecimento da cidadania, a noção de direitos torna-se mais expressiva quando surge a clareza por parte dos indivíduos de que é um direito ter os direitos respeitados, em outros termos o direito de ter os direitos. Portanto, outra noção importante é sua historicidade. Suas concepções se alteram, a qualidade da cidadania se altera.

Historicamente, o Estado demora em reconhecer direitos e só o faz diante da pressão da sociedade. A história da cidadania no mundo ocidental (PINSKY; BASSANEZI PINSKY, 2003, BOBBIO, 1992, KROHLING, 2009) mostra que as lutas para o reconhecimento e a ampliação do seu status - ou a qualidade da cidadania - são antigas e as conquistas são lentas.

A história do desenvolvimento dos direitos do citadino, a evolução da cidadania na Europa centro-ocidental, transcorre há pelos menos três séculos - de acirrados conflitos sociais -, relacionada à conquista de três conteúdos básicos 
de direitos, diversos entre si: os direitos civis, no século XVIII; os direitos políticos no século XIX; e os direitos sociais, no século XX (MONDAINI, 2003, p. 116).

Motins, revoltas, embates políticos, greves, lockout (a greve patronal), coerção e repressão marcam toda a história das lutas por direitos sociais e por políticas públicas que os garantam, pois nas sociedades marcadas por antagonismos e a supremacia de uns sobre os outros, os direitos igualitários só existem se forem conquistados. Portanto, são as lutas sociais que empurram para a frente as noções de direito na visão do Estado e dos próprios cidadãos.

No Brasil, só em 1932 foi reconhecido o direito de voto da mulher e o do analfabeto, só na Constituição de 1988. O direito à greve foi conquistado só em 1978 (SINGER, 2003). Os direitos à moradia e à igualdade, entre outros, ainda são negados a grandes contingentes da população brasileira.

Cidadania tem duas faces, pois implica direitos, mas também deveres. Razão pela qual, ela também pode ser compreendida a partir de dois eixos: o civil e o cívico. O eixo civil (VIEIRA, 2000) corresponde à esfera dos direitos individuais (de votar e ser votado, de locomoção, de liberdade de expressão, acesso a serviços públicos etc.), sob a garantia do Estado, além da responsabilidade individual pelos próprios atos, o cuidado com a família e a expressão de reivindicações. O eixo cívico comporta os deveres da cidadã e do cidadão ${ }^{2}$ para com o Estado, como guardião do bem público, ou, em outros termos, dos macrointeresses da coletividade.

Ainda segundo Vieira (2000), em Richard Morse a tradição cívica é muito diferente da tradição civil da modernidade, com o Estado garantindo os direitos individuais da pessoa.

A tradição cívica coloca-se mais do ponto de vista do Estado do que do cidadão. (...) A atitude contemporânea que parece prevalecer é a busca de uma estratégia para combinar o civil - direitos individuais - e o cívico - deveres para com o Estado, responsável pelo bem público (VIEIRA, 2000, p. 25).

Em complemento, se esclarece que a dimensão cívica conduz à responsabilização e refere-se à obrigação, o que quer dizer dos deveres de todos os cidadãos, dos governos e das instituições públicas e privadas, no respeito ao interesse coletivo e aos valores máximos de uma sociedade, a ordem civilizatória. Em última instância, civilidade se expressa na superação da consciência individual em favor do interesse coletivo, como a solidariedade social e responsabilização pela coisa pública.

Esse sentido elevado segundo Vieira (2000, p. 27), de civilidade, aproxima-se do que Montesquieu chamou de virtude:

2 Doravante usaremos este termo ou termos semelhantes só no masculino para evitar redundância textual. 
amor à República e à Democracia. Civilidade, em suma, é a conduta de uma pessoa cuja autoconsciência individual está parcialmente sobredeterminada por sua consciência coletiva, sendo os referentes desta última a sociedade como um todo e as instituições da sociedade civil ${ }^{3}$.

\section{As limitações do respeito à diversidade em organizações}

Os elementos da cidadania mostrados acima ajudam a pensar o papel das organizações como, por exemplo, as indústrias mediáticas tradicionais e os sites de mídias sociais digitais que priorizam o negócio em detrimento dos valores culturais favoráveis à equidade social e à formação educacional para a civilidade. Ao priorizarem os interesses do capital, na lógica do modo de produção capitalista, acabam incentivando o individualismo, o hedonismo, a competição e o consumismo. Também as demais empresas, ao se moverem segundo os interesses de mercado, movidas pelo interesse ilimitado do lucro, percorrem esse mesmo caminho violando os interesses coletivos da sociedade de onde extraem sua riqueza, por exemplo, ao burlar direitos trabalhistas, discriminar trabalhadores devido as suas condições étnico-raciais e sociais, adotar posturas depredatórias do meio ambiente. O fato de essa lógica ser inerente ao capitalismo não exime as empresas de responsabilidade social, em especial, na "era dos direitos” (BOBBIO, 1992) experimentada na contemporaneidade.

A era de direitos de que fala Bobbio (1992) inclui o reconhecimento de direitos não só no nível individual, mas coletivo. Assim, todo tipo de preconceito e discriminação é contra os direitos, não apenas os individuais, mas dos grupos humanos, sejam eles os pobres, os nordestinos, as mulheres, os negros, as pessoas com deficiência e assim por diante. Na prática, nem sempre esses direitos são respeitados. No contexto societário amplo persistem valores tradicionais nem sempre condizentes aos avanços históricos (BOBBIO, 1992, VIEIRA, 2000) nas concepções de cidadania. Para Cortina (2005, p. 18), referindo-se a Bell ${ }^{4}$, “o sistema econômico e político estão [...] dependendo de uma revolução cultural que assegure a civilidade, a disponibilidade dos cidadãos a se comprometerem com a coisa pública”.

Uma das dimensões dessa nova era de direitos diz respeito à afirmação das identidades e da diversidade. A Organização das Nações Unidas para Educação, Ciência e Cultura (UNESCO) tem se dedicado ao tema há décadas. Em 1978, publicou a Declaração da UNESCO sobre a Raça e os Preconceitos Raciais (DECLARAÇÃO DA UNESCO ..., 1978), em cujo artigo $3^{\circ}$ estabelece que

é incompatível com as exigências de uma ordem internacional justa e que garanta o respeito aos direitos humanos toda distinção, exclusão, restrição

3 Sociedade civil “é aqui concebida não apenas como mercado, mas como espaço além da família e da localidade e aquém do Estado, significando ainda boas maneiras com os amigos e tolerância com os inimigos” (SHILLS apud. VIEIRA, 2000, p. 27).

4 Bell (1977). 
ou preferência baseada na raça, na cor, na origem étnica ou nacional, ou na tolerância religiosa motivada por considerações racistas [...], que limita de um modo arbitrário ou discriminatório o direito ao desenvolvimento integral de todos os seres e grupos humanos; este direito implica um acesso em plena igualdade dos meios de progresso e de realização coletiva e individual [...].

Em 2002, a UNESCO divulgou a Declaração Universal sobre a Diversidade Cultural ao reafirmar o seu compromisso com a plena realização dos direitos humanos e das liberdades fundamentais proclamadas na Declaração Universal dos Direitos Humanos, de 1948, adenda a defesa da diversidade cultural, o que reforça as concepções de direitos de cidadania. No artigo $4^{\circ}$, diz:

A defesa da diversidade cultural é um imperativo ético, inseparável do respeito pela dignidade da pessoa humana. Implica o compromisso de respeitar os direitos humanos e as liberdades fundamentais, em particular os direitos das pessoas que pertencem a minorias e os dos povos autóctones. Ninguém pode invocar a diversidade cultural para violar os direitos humanos garantidos pelo direito internacional, nem para limitar seu alcance (DECLARAÇÃO UNIVERSAL ... 2002).

Portanto, se pode inferir que diversidade não é uma palavra de ordem, nem uma palavra que está apenas na moda. Ela remete aos direitos da pessoa, remete à igualdade entre os povos e entre os seres humanos em todos os sentidos. Igualdade entre homem e mulher, entre brancos e negros, pessoas sem e com deficiências, diferenças entre pessoas heterossexuais e $L G B T I^{5}$, de idade, escolaridade, religião, aparência, peso, procedência e assim por diante.

Pesquisa realizada pelo Instituto Ethos de Empresas e Responsabilidade Social e pelo Banco Interamericano de Desenvolvimento (BID) sobre o "Perfil social, racial e de gênero das 500 maiores empresas do Brasil e suas ações afirmativas” apresenta entre seus resultados o seguinte:

- Apenas 2\% dos funcionários das maiores empresas brasileiras são pessoas com deficiência (o mínimo exigido pela lei $n^{0}$ 8.213/1991) em seus quadros. Os homens são maioria nesse contingente, com proporção de 59,9\%, e as mulheres, com participação de 40,1\%;

- As mulheres representam 58,9\% dos estagiários, 42,6\% dos trainees e 55,9\% dos aprendizes, mas ocupam apenas 13,6\% das vagas executivas, 31,3\% das vagas de gerência, e 38,8\% de supervisão. Dos postos no Conselho de Administração só $11,0 \%$ são de mulheres;

5 Lésbicas, gays, bissexuais, transgêneros e intersexuais. 
- As mulheres recebem $70 \%$ da massa salarial obtida pelos homens;

- Não existe um executivo de origem indígena nas empresas estudadas;

- 94,2\% dos cargos executivos, 90,1\% de gerência e 72,2\% de supervisão pertencem a brancos, enquanto apenas 4,7\% dos negros ocupam cargos executivos, $6,3 \%$ de gerência e 25,9\% de supervisão (INSTITUTO ETHOS, 2016).

Estes dados são expressivos na revelação da existência de discriminação no mundo empresarial de segmentos sociais que historicamente sofrem preconceitos no Brasil. Como explicar, a partir dos dados da referida pesquisa, que os negros estejam em tão grande desiquilíbrio em relação aos brancos no exercício de cargos de liderança? Como explicar que as mulheres recebam menos por trabalho igual ao dos homens? Possivelmente, a reprodução de valores preconceituosos que perpassam as culturas e a sociedade ajuda a entender 0 fenômeno, no entanto, sua não legitimidade é questão de tempo ${ }^{6}$.

Na parte analítica da referida pesquisa (INSTITUTO ETHOS, 2016, p. 15), comentase sobre a inclusão de negros:

os negros, que são 52,9\% da população do país, estão, como as mulheres, em situação de desigualdade, sub-representação e afunilamento hierárquico. A exclusão é, entretanto, mais acentuada. Maioria nos contingentes de aprendizes e trainees, com proporção de 57,5\% e 58,2\%, os negros têm sua participação resumida a $6,3 \%$ na gerência e $4,7 \%$ no quadro executivo.

Quanto às mulheres,

com maioria de 51,4\% da população brasileira, estão sub-representadas nesse grupo e, além da desigualdade em relação aos homens, enfrentam um afunilamento hierárquico que as exclui, em maior proporção, dos postos mais elevados da escala hierárquica, como já se observara nas pesquisas anteriores (INSTITUTO ETHOS, 2016, p. 15).

Por outro lado, a discriminação não se manifesta apenas no nível institucional, mas também entre os colegas de trabalho, cujos preconceitos em relação a mulheres, negros, LGBTIs, pessoas com deficiência, além de fatores como idade, escolaridade, religião, peso e aparência, dificultam o relacionamento interno em uma empresa. Portanto, o fator cultural é um limitador a ser equacionado nos programas de inclusão empresarial.

As mudanças de visões e práticas empresariais ocorrem por pressão social. Para tanto, a sociedade civil se mobiliza e os movimentos sociais são uma das formas de organização que impulsionam a sociedade a avançar no respeito aos direitos das pessoas e do meio ambiente.

6 Recomenda-se assistir o vídeo "Igualdade H-M no trabalho", que mostra a desigualdade de gênero no olhar de crianças e préadolescentes. Disponível em: https://www.youtube.com/watch?v=VbIc4GDpIkQ. Acesso em: 13 jul. 2021. 
Os exemplos podem ser identificados nos movimentos sindicais, movimentos ecológicos, de mulheres, negros, indígenas, imigrantes e LGBTIs, entre outros. Com eles, o Brasil avançou na promulgação de leis de proteção civil, em consonância com a Constituição Federal, como a lei que exige a contratação de pessoas com deficiências - Lei no 8.213/19917; o Estatuto do Idoso - Lei $n^{0} 10.741 / 03$, de $1^{\circ}$ de outubro de 2003, que regula e assegura direitos das pessoas com idade acima de 50 anos $^{8}$; o Estatuto da Criança e do Adolescente - Lei no 8.069, de 13 de julho de 1990 que dispõe sobre a proteção integral à criança e ao adolescente ${ }^{9}$; e a Lei Maria da Penha - Lei n ${ }^{0}$ 11.340, de 7 de agosto de 2006, que institui mecanismos para coibir a violência doméstica e familiar contra a mulher ${ }^{10}$.

Estas são leis importantes que regulam e instituem direitos de segmentos vulneráveis da sociedade, o mínimo necessário para mudar as práticas discriminatórias, tanto no âmbito no mundo do trabalho quanto no das relações familiares e no conjunto da sociedade, sejam elas machistas, homofóbicas, racistas, gordofóbicas ou de outra natureza. Se para transformar a cultura das pessoas e das instituições o processo é lento, as leis ajudam o país a avançar, pois se o respeito não se dá pela força que o direito humano possui em si mesmo, que venha a lei para punir os atores das violências de todo tipo.

Além das noções de direitos já apontadas, convém acrescentar a demanda pelo respeito às culturas dos trabalhadores e dos povos nas localidades onde as empresas se instalam. Essas violações culturais são comuns quando da implantação de empresas em áreas estratégicas sem levar em conta as reais condições em relação à preservação do meio ambiente e as demandas da população local, a exemplo da construção de usinas hidrelétricas, como é o caso de Belo Monte ${ }^{11}$ na Amazônia brasileira. Outros focos de violações dos interesses e condições locais ocorrem quando da internacionalização de empresas, pois a tendência predominante é “invadir” o local através da imposição de regras, valores e conhecimento (desenho arquitetônico de construções) elaborados na unidade matriz da corporação para todos os lugares onde ela passa a atuar. No campo da mineração, a Vale em Moçambique é um exemplo. As críticas apontam danos ao meio ambiente e as precárias condições de vida de famílias num megaprojeto que prometeu desenvolvimento. A empresa chegou a tirar famílias dedicadas à produção agrícola de terras onde ela opera minas de carvão, reassentando-as em terras impróprias à agricultura ${ }^{12}$, entre outros aspectos. Esta mesma empresa acaba de demonstrar, no Brasil, mais especificamente em Brumadinho, estado de

7 A Lei 8.213/1991 estabelece percentuais mínimos de contratação de empregados com deficiências físicas: de empresa com 100 ou mais empregados exige-se o preenchimento de $2 \%$ a $5 \%$ de seus cargos com beneficiários reabilitados ou pessoas com deficiência, habilitadas, nesta proporção: até 200 empregados, 2\%; de 201 a 500, 3\%; de 501 a 1.000, 4\%; e, acima de 1.000, 5\%. Contudo, conforme pesquisa realizada (INSTITUTO ETHOS, 2016), a maioria das empresas cumpre apenas os percentuais mínimos exigidos, e, segundo se sabe, é para evitar complicações judiciais.

8 Disponível em: https://presrepublica.jusbrasil.com.br/legislacao/98301/estatuto-do-idoso-lei-10741-03. Acesso em: 9 jul. 2018

9 Disponível em: https://presrepublica.jusbrasil.com.br/../estatuto-da-crianca-e-do-adolescente-lei-8069. Acesso em: 9 jul. 2018.

10 Disponível em: http://www.planalto.gov.br/ccivil_03/_ato2004-2006/2006/lei/l11340.htm. Acesso em: 9 jul. 2018.

11 Disponível em: https://www.cpalsocial.org/documentos/393.pdf e em: https:/pt.mongabay.com/2017/02/brasil-desprovidobarragem-belo-monte-devastadora-as-culturas-indigenas/. Acesso em: 9 jul. 2018.

12 Disponível em: http://br.rfi.fr/africa/20160124-mina-da-vale-em-mocambique-e-criticada-ha-quase-cinco-anos. Acesso em: 9 jul. 2018. 
Minas Gerais, a sua extrema falta de responsabilidade social, humana, ambiental e ética pelas condições de risco com que mantém suas operações mineradoras. Os contrastes entre o seu discurso institucional e a prática são evidenciados ao mundo pela força da realidade. A destruição do meio ambiente e de cerca de quatro centenas de vidas humanas, além da vida animal, é a prova que põe em xeque qualquer argumentação comunicacional que camufla o que ocorre na prática. Do ponto de vista das Relações Públicas, antes de dizer que se protege o meio ambiente, tem que, de fato, protegê-lo.

\section{Discurso das organizações sobre diversidade}

Em processo semelhante ocorre o tratamento da questão das diversidades nas organizações. Não é raro que existam apenas vestígios do respeito à diversidade, seja ela de gênero, étnica ou de condição física, para cumprir exigências legais e/ou para atualizar as narrativas, mas de fato o respeito às diferenças, em condição de igualdade, ainda não é incorporado como política efetiva e como parte da cultura organizacional no Brasil, salvo raras exceções.

Sinais de incorporação de políticas de diversidade nas empresas remontam a meados do século XX, nos Estados Unidos, com dois marcos importantes. Em 1941, o então presidente Franklin D. Roosevelt assinou a Ordem Executiva 8.802, vetando a discriminação racial nas Forças Armadas, portanto, proibindo a discriminação no emprego. No ano de 1955, a luta antissegregacionista ganha força com a costureira Rosa Parks, que se recusou a ceder o assento num ônibus a um homem branco. Na década de 1960, Martin Luther King lidera a Marcha sobre Washington (em 1963), de cerca de 150 mil pessoas. Nessa mesma década, crescem as reivindicações pelo direito ao trabalho, pelo fim da discriminação e pelo reconhecimento do direito ao voto das pessoas negras. A inclusão das mulheres ao grupo de beneficiários das ações afirmativas é oficializada em 1965, pelo presidente Lyndon B. Jonhson, através da Ordem Executiva 11.246 (SALES, 2018). Processos semelhantes, com a fixação de exigências de contratação de pessoas com deficiências, mulheres, indígenas, e a não-discriminação por religião, ocorreram no Canadá e na Irlanda.

Foram as multinacionais, principalmente as norte-americanas, que trouxeram ao Brasil o tema da diversidade nas organizações, com mais intensidade nos anos 1990 (SALES, 2018), mas as ações afirmativas (intervenção política para reverter o quadro de desigualdades) foram impulsionadas pela Constituição brasileira de 1988 e pelos movimentos sociais que, além de denunciar o descumprimento da Convenção número 111 da Organização Internacional do Trabalho no tocante às relações de emprego (TEIXEIRA, 2011), são propositivos em termos de elaboração de leis e ações concretas junto às pessoas com os direitos violados.

O discurso dominante das organizações e/ou de mentores intelectuais defensores da diversidade nas organizações se, por um lado, condiz com a lógica do capitalismo, por outro, mostra insensibilidade para com a causa dos direitos humanos como dimensão cívica. Falase em "gestão da diversidade", de "inclusão social” e em "respeito à diversidade" como 
estratégia competitiva (COX JR.; BLAKE, 1991, GILBERT; STEAD; IVANCEVICH, 1999). Ou seja, o proceder empresarial em favor de práticas inclusivas em relação a admissibilidade de negros e de pessoas com deficiências etc. é defendido porque isso resultaria em vantagem competitiva. Empresa que assim se comporta demonstraria possuir uma nova visão de gestão, uma visão tida como inovadora, capaz de corresponder à pressão social e, ao mesmo tempo, lucrar mais. Nessa lógica, há uma redução da desigualdade como estratégia interessada em melhorar o desempenho econômico e a reputação na sociedade, sem a incorporação nas noções de cidadania.

Em outros termos, nessa perspectiva, há a defesa de que a incorporação de pessoas “diferentes” por suas diversas condições criaria um clima de motivação entre os funcionários, e de que a diversificação da equipe contribuiria para melhorar o desempenho, além de abrir novos segmentos de mercado. Seria uma forma de manter e/ou conquistar novos clientes, dada a reputação favorável transmitida, inclusive, pelos próprios funcionários “incluídos”. Portanto, o que motivaria o respeito à diversidade é fundamentalmente a vantagem que ela traz em relação à lucratividade e não pelo valor e necessidade da pessoa humana, do ponto de vista da ética cívica ou da coletividade. Porém, como diz Casali (2008), o que deve estar em questão hoje em dia, devido às mudanças de visão societária ${ }^{13}$, não é mais apenas o interesse dos acionistas, nem dos públicos principais, mas o da coletividade, da universalidade. Trata-se de uma ética que se recoloca historicamente no presente. Ética é "um conjunto de referências, princípios e disposições voltados para a ação para balizar as ações humanas entre o supostamente correto e o incorreto, o supostamente bom e o mau, o supostamente justo e injusto” (CASALI, 2008, p. 53).

Teóricos que defendem a perspectiva da "gestão da diversidade” chegam a sistematizar quais seriam os benefícios para as empresas, no tocante ao desempenho econômico, da inclusão de "minorias”, a exemplo de Cox Jr. e Blake (1991), apontam as seguintes vantagens : a) Custo - Como a satisfação no trabalho tende a ser menor entre mulheres e negros do que para homens brancos, a implementação de programas na lógica de "gestão da diversidade" (creches, por exemplo) tende a mudar o quadro e favorecer a redução de custos com turnover e absenteísmo; b) Recurso aquisição - Desenvolvimento da reputação como empregadores de mulheres e minorias étnicas ajuda na atração de funcionários talentosos; c) Marketing Sensibilização para as novas culturas que formam o mercado; d) Criatividade - Diversidade de perspectivas e menor ênfase na conformidade com normas do passado aumenta a criatividade e a inovação na empresa; e) Resolução de problemas - A heterogeneidade em grupos de decisão aumenta a capacidade de resolução e redução de problemas; f) Flexibilidade - A diversidade de argumentos e a operação de sistema menos padronizado e, portanto, mais fluido, favorece maior flexibilidade para reagir a mudanças socio-ambientais.

Como se pode ver, o enfoque acima é basicamente funcionalista e prescritivo na tentativa de mostrar as vantagens competitivas e, consequentemente, econômicas da aplicação

13 Refere-se a questão da sustentabilidade, das exigências de respeito à diversidade, distribuição de renda básica social aos empobrecidos etc. 
de políticas empresariais em favor da diversidade. Essa visão fere a ética da universalidade ao não levar em conta os princípios cívicos da cidadania.

Contudo, a implantação da gestão da diversidade, como mostram Alves e GaleãoSilva (2004), não é fácil no ambiente laborativo. Dentre os principais obstáculos apontados, os autores, referindo-se a Austin (1997), Milliken e Martin (1996), Barry e Bateman (1996) e Wise e Tschirhart (2000), indicam o ceticismo dos próprios funcionários das empresas em relação aos programas e à sua efetividade; atitudes preconceituosas em relação a colegas ou chefes que são beneficiários desses programas; e as dificuldades em modificar rotinas de administração de recursos humanos para incluir a questão da diversidade. Nesse contexto, mudanças são necessárias e vão além de meros procedimentos administrativos, abrangendo mudanças culturais (GILBERT; STEAD; IVANCEVICH, 1999) e cognitivas (SCHNEIDER; NORTHCRAFT, 1999). Cabe aos profissionais de Relações Públicas, entre outros, estarem atentos a tais mudanças necessárias no conjunto das organizações, mas também em suas próprias visões e padrões de comportamento no estabelecimento de programas de relacionamento com os públicos. A adesão cega aos preceitos empresarias arcaicos não faz jus aos novos tempos que demandam respeito às diferenças e à ética empresarial.

Na prática, se por um lado, empresas adotam ações afirmativas (critérios de equidade nas relações de emprego) como estratégia competitiva, por outro lado, há aquelas que aderem a ações afirmativas no sentido restrito de cumprimento das leis na intenção de evitar processos na justiça (SALES, 2018) reclamantes de direitos.

\section{Diversidade versus meritocracia}

A dicotomia sugerida neste intertítulo se funda na rejeição de políticas públicas de “ação afirmativa”, pois esta seria contrária aos princípios da meritocracia. As políticas e ações afirmativas, ou o resguardo legal de instituição de sistemas de obrigatoriedade de inclusão de pessoas com deficiência pelas empresas e de quotas para alunos negros em universidades públicas, entre outros, chegam a ser vistos como algo prejudicial às pessoas de grupos discriminados, pois influenciariam negativamente, principalmente os jovens, no seu desenvolvimento. A visão é de que estes têm condições de vencer pelo mérito e de que fazem jus à igualdade por competência, sem depender de regalias institucionalizadas.

Sem duvidar dessas capacidades, convém lembrar que a defesa da meritocracia vencer pelo mérito - esconde que as desigualdades, como aquelas expressas nas condições de existência de pobreza e de violência, são obstáculos reais a maioria das pessoas que vive nessas condições. Para os jovens pobres, negros, meninas e indígenas, vencer pelo próprio mérito significa a necessidade de esforço muito maior e muita privação, em relação aos jovens filhos de pais da classe média, para poderem estudar em universidades e, pouco a pouco, galgar postos de trabalho bem remunerados ${ }^{14}$. Então, a ideologia neoliberal, que

14 Sugere-se ver o vídeo "A tragédia neoliberal e a meritocracia”, por Marilena Chauí sobre meritocracia. Disponível em: https:// www.youtube.com/watch?v=5jNea8b3hUE. Acesso em: 9 jul. 2018. 
prega a meritocracia, naturaliza a desigualdade e tenta fazer crer que problema dos que não conseguem “vencer” está em cada um e não no sistema gerador das contradições, quando são estas que impedem a equidade social.

A defesa da "gestão da diversidade" também parte da noção de “democracia racial”, um engodo para fazer crer que a discriminação não existe e, portanto, não leva em conta a desigualdade que existe de fato; por exemplo, a taxa de analfabetismo é mais elevada entre os negros e pardos $(9,9 \%)$ do que entre os brancos $(4,2 \%)^{15}$ (PNAD CONTÍNUA ..., 2017). Entre a população pobre, os jovens negros são os mais assassinados: a cada 23 minutos um jovem negro é assassinado no Brasil (CHEGA DE RACISMO..., 2017).

Quanto à pobreza, 52,1 milhões de brasileiros, um quarto da população, viviam em situação de pobreza ${ }^{16}$ em 2016 e 64,9\% tinham restrição de acesso a pelo menos um dos direitos, como educação, proteção social, moradia adequada, serviços básicos de saneamento e internet, segundo dados do IBGE ${ }^{17}$ (SÍNTESE DE INDICADORES..., 2017).

Assim sendo, o enfrentamento aos problemas da discriminação, ao ser tomado apenas do ponto de vista das vantagens competitivas que as empresas podem usufruir ou quando correspondem ao cumprimento de leis afirmativas, mesmo com a instituição de políticas dentro da chamada "gestão da diversidade”, não se assume a responsabilização pública na constituição da equidade social, da igualdade como um direito de todos.

Por outro lado, convém ressaltar que a gestão com respeito à diversidade também se depara com outros obstáculos. No nível interno das organizações há rotinas viciadas em visões tradicionais da diferença, há ceticismo e também preconceitos com os colegas, subordinados ou chefes. Por exemplo, em relação à condição da própria pessoa (com deficiência, cor, sexo, origem étnica, procedência territorial etc.) e mesmo o desprezo ao se reduzir o valor e capacidades das pessoas por serem beneficiárias de determinados programas inclusivos. As quotas para afrodescendentes nas universidades são um exemplo. Estudantes quotistas precisam provar que são capazes de sobressair intelectualmente diante dos demais para serem respeitados pelos próprios colegas, professores e pelas instituições.

No tocante à gestão, há entre as visões de níveis hierárquicos gerenciais a de que a adoção das medidas regidas pelas políticas afirmativas se justifica para se evitar processos judiciais e, consequentemente, sofrer desgastes na reputação e gastos financeiros. Portanto, o fator de decisão mais importante sobre a implementação de políticas inclusivas tem sido mais uma vez o interesse econômico empresarial e não o valor intrínseco das pessoas e os direitos delas a tratamento igualitário no âmbito das organizações.

15 Precisamente, diz o IBGE: "A taxa de analfabetismo para os homens com 15 anos ou mais de idade foi de 7,4\% e para as mulheres $7,0 \%$. Entre as pessoas de cor preta ou parda $(9,9 \%)$ a taxa foi mais que o dobro das pessoas de cor branca, $(4,2 \%)$. Entre os idosos de 60 anos ou mais, essa taxa foi de 11,7\% para a população branca e 30,7\% para os pretos e pardos” (PNAD Contínua 2016). Acesso em: 9 jul. 2018.

16 É considerado pobre quem vive com menos de US\$ 5,5 por dia.

17 Instituto Brasileiro de Geografia e Estatística. 
Contudo, a pertinência das críticas acima não reduz o reconhecimento dos ganhos proporcionados pelos programas de diversidade implementados em algumas organizações.

No Brasil, onde não houve ações afirmativas efetivas, os programas de diversidade teriam o mérito de trazer benefícios a algumas pessoas discriminadas, uma vez que, por meio de iniciativas de gestão da diversidade, essas mesmas pessoas podem conseguir seu primeiro emprego, ou direitos que lhes são negados cotidianamente (ALVES; GALEÃO-SILVA, 2004, p. 10).

O importante é que ao lado das ações afirmativas haja o desenvolvimento da percepção da ética da universalidade como estratégia para a felicidade, como direito de todos.

Quem administra as organizações e quem institui programas de relacionamentos comunicativos e de relações públicas internos e externos são pessoas, ou seja, a gestão não é feita por entes imateriais. Apesar de estarem sujeitas aos condicionamentos sociais, culturais e organizacionais, os gestores são desafiados a se desvencilharem de visões preconceituosas que violam os princípios da cidadania. Estar no mundo é mais do que apropriar-se de suas potencialidades, como, por exemplo, da mão de obra e das riquezas naturais e tecnológicas. É ajudá-lo a melhorar em dignidade para todos. A responsabilidade é de todos e os ganhos são de todos também.

Nesse sentido, é importante que haja mudança na concepção de mundo geral e sobre o papel das organizações, principalmente dos próprios proprietários, acionistas, gestores e funcionários. Mudanças na cultura cognitiva e no conhecimento, além de mudanças dos mecanismos prescritivos que influenciam as práticas organizacionais. É uma questão de sintonia com um novo tempo histórico. Como diz Cortina (2005, p. 86),

é inteligente ter uma conduta ética, construindo 'empresas cidadãs'. Algo que pode ser feito, entre outras razões, porque não só mudou o conceito de empresa (...) como o de ética. A tradicional ética individual, da conviç̧ão e do interesse do outro, foi complementada por uma ética das instituições, da responsabilidade e do interesse universalizável.

No fundo, trata-se de investir em responsabilidade social, não apenas para cumprir minimamente preceitos jurídicos e evitar processos judiciais, mas como estratégia para a longevidade da empresa e prosperidade dela e da sociedade. Se houver

lucidez na montagem da equação, há muitos benefícios a colher. Na economia do conhecimento e no capitalismo "social”, a inteligência das relações sociais aponta indubitavelmente para a sabedoria ética, ou melhor, para decisões que se orientem pelo respeito aos outros e pela contribuição ao bem-estar coletivo (SROUR, 2003, p. 411). 


\section{Considerações finais}

A cidadania pode ser mais bem compreendida se tomada na perspectiva da dupla intersecção entre os direitos civis e os direitos cívicos. Enquanto os primeiros dizem respeito diretamente às conquistas que melhoram o status de cidadania, os direitos cívicos remetem a um sentido universalizante dos direitos da pessoa, de um povo e da própria espécie humana.

Civilidade é caminho e estratégia da humanidade. No contexto na sociedade brasileira atual, há avanços em políticas afirmativas instituídas desde o início deste século, embora também se verifiquem, nos últimos anos, alguns retrocessos em políticas públicas que acabam por reduzir ganhos históricos em matéria de direitos dos trabalhadores e de benefícios sociais, os quais não podem ser naturalizados. Do mesmo modo, há que se indignar com posturas conservadores de pessoas, principalmente de políticos profissionais ${ }^{18}$ e até de juízes ${ }^{19}$, porque afrontam direitos consagrados na Constituição brasileira, e por serem anticívicas. Os direitos humanos estão acima de posições e convicções pessoais, pois se encoram em códigos legais e preceitos justos como direitos da pessoa realmente aceitos e regulados.

Desde a Declaração de Independência dos Estados Unidos (1776), a Declaração dos Direitos do Homem e do Cidadão de 1789, na França, até a Declaração Universal dos Direitos Humanos, adotada e proclamada pela Assembleia Geral das Nações Unidas em 10 de dezembro de 1948, há clara e enfática defesa dos direitos naturais da pessoa e da igualdade entre elas - sem distinção de qualquer espécie, seja de raça, cor, sexo, idioma, religião, opinião política ou de outra natureza, origem nacional ou social, riqueza, nascimento, ou qualquer outra condição, como inalienáveis.

São princípios cuja observância é de responsabilidade de todos e, como tal, das organizações privadas e públicas que lidam com pessoas e interferem no meio ambiente. Lembrando que tais organizações não funcionam ao acaso. Elas são geridas por pessoas, e pela confluência da ação de profissionais qualificados. A responsabilidade também cabe a cada um/a. Antes da função que exerce está o seu papel como cidadã/cidadão, sua corresponsabilidade moral e cívica. Em vez de retroceder, o caminho natural é avançar no respeito aos direitos humanos sociais, que representam conquistas da humanidade ao longo dos séculos.

\section{Referências}

ALVES, M. A.; GALEÃO-SILVA, L. G. A crítica da gestão da diversidade nas organizações. RAE - Revista de Administração de Empresas, São Paulo, FGV, v. 44, n. 3, p. 1-12, 2004. Disponível em: http://www.fgv. br/rae/artigos/revista-rae-vol-44-num-3-ano-2004-nid-45993/. Acesso em: 2 maio 2018.

AUSTIN, J. R. A cognitive framework for understanding demographic influences in groups. International Journal of Organizational Analysis, v. 5, n. 4, p. 342-359, 1997.

18 Ou seja, existem figuras públicas que externam atitudes machistas e racistas em agressão a mulheres, pobres, quilombolas, nordestinos etc., um sinal de afronta ao respeito aos direitos da pessoa.

19 Certo juiz considera que a Lei Maria da Penha é “destruidora de lares”... Disponível em: https://revistagalileu.globo.com/Sociedade/ noticia/2018/02/entrevista-com-juiz-gilvan-macedo-dos-santos.html. Acesso em: 28 jun. 2018. 
BARRY, B.; BATEMAN, T. S. A social trap analysis of the management of diversity. The Academy of Management Review, v. 21, n. 3, p. 757-791, 1996.

BARBALET, J. M. A cidadania. Lisboa: Editorial Estampa, 1989.

BELL, D. Las contradicciones culturales del capitalismo. Madrid: Alianza, 1977.

BOBBIO, N. A era dos direitos. 4a. reimp. Rio de Janeiro: Campus, 1992.

CASALI, A. Ética e sustentabilidade nas relações públicas. Organicom-Revista Brasileira de Comunicação Organizacional e Relações Públicas, São Paulo, a. 5, n. 8, p. 48-58, 2008.

CHEGA DE RACISMO. Jovem negro vivo é potência! Geledés - Instituto da Mulher Negra. São Paulo: Geledés, 25 jul. 2017. Disponível em: https://www.geledes.org.br/chega-de-racismo-jovem-negro-vivo-epotencia/. Acesso em: 9 jul. 2018.

CONSTITUIÇÃO DA REPUBLICA FEDERATIVA DO BRASIL, Brasília: Senado Federal, 2016.

CORTINA, A. Cidadãos do mundo: para uma teoria da cidadania. São Paulo: Loyola, 2005.

COX JR., T.; BLAKE, S. Managing diversity: implications for organizational competitiveness. Academy of Management Executive, v. 5, n. 3, p. 45-57, 1991.

DECLARAÇÃO UNIVERSAL DOS DIREITOS HUMANOS (1948). Brasília: Representação da Unesco no Brasil, 1998.

DECLARAÇÃO DA UNESCO SOBRE A RAÇA E OS PRECONCEITOS RACIAIS. UNESCO. São Paulo: Biblioteca Virtual de Direitos Humanos da USP. Disponível em: www.direitoshumanos.usp.br/index.php/ UNESCO-Organização-das-Nações... Acesso em: 25 jan. 2021.

DECLARAÇÃO UNIVERSAL SOBRE A DIVERSIDADE CULTURAL. UNESCO, 2002. Disponível em: www.unesco.org/.../CLT/diversity/pdf/declaration_cultural_diversit... Acesso em: 25 jan. 2021.

GILBERT, J. A.; STEAD, B. A.; IVANCEVICH, J. M. Diversity management: a new organizational paradigm. Journal of Business Ethics, v. 21 n. 1, p. 61-77, 1999.

INSTITUTO ETHOS. Perfil social, racial e de gênero das $\mathbf{5 0 0}$ maiores empresas do Brasil e suas ações afirmativas. São Paulo: Instituto Ethos e Banco Interamericano de Desenvolvimento (BID), maio de 2016. Disponível em: https://issuu.com/institutoethos/docs/perfil_social_tacial_genero_500empr. Acesso em: 16 maio 2018.

KROHLING, A. Diretos humanos fundamentais. Diálogo intercultural e democracia. São Paulo: Paulus, 2009.

MARSHALL, T. H. Cidadania, classe social e status. Rio de Janeiro: Zahar, 1967.

MILLIKEN, F. J.; MARTIN, L. L. Searching for common threads: understanding the multiple effects of diversity in organizational groups. The Academy of Management Review, v. 21, n. 2, p. 402-434, 1996.

MONDAINI, M. O respeito aos direitos dos indivíduos. In: PINSKY, J.; BASSANEZI PINSKY, C. História da cidadania. São Paulo: Contexto, 2003. p. 115- 133.

PINSKY, J. Introdução. In: PINSKY, J.; BASSANEZI PINSKY, C. História da cidadania. São Paulo: Contexto, 2003. p. 9-13.

PINSKY, J; BASSANEZI PINSKY, C. História da cidadania. São Paulo: Contexto, 2003.

PNAD Contínua 2016: 51\% da população com 25 anos ou mais do Brasil possuíam apenas o ensino fundamental completo. Agência IBGE Notícias, 21 dez. 2017. Disponível em: https://agenciadenoticias.ibge.gov.br/agencianoticias/2013-agencia-de-noticias/releases/18992-pnad-continua-2016-51-da-populacao-com-25-anos-oumais-do-brasil-possuiam-apenas-o-ensino-fundamental-completo.html. Acesso em: 14 jul. 2018. 
SALES, R. G. de. Diversidade nas organizações: das lutas sociais às políticas públicas. In: CONGRESSO ABRAPCORP, XII, Goiânia (GO), Abrapcorp e Faculdade de Informação e Comunicação da Universidade Federal de Goiás, 16 a 18 de maio de 2018. Anais....

SCHNEIDER, S. K.; NORTHCRAFT, G. B. Three social dilemmas of workforce diversity in organizations: a social identity perspective. Human Relations, v. 52, n. 11, p. 1445-1468, 1999.

SINGER, P. A cidadania para todos. In: PINSKY, J.; BASSANEZI PINSKY, C. História da cidadania. São Paulo: Contexto, 2003. p. 191-263.

SÍNTESE DE INDICADORES SOCIAIS: uma análise das condições de vida da população brasileira: 2017. IBGE - Coordenação de População e Indicadores Sociais. Rio de Janeiro: IBGE, 2017, 147 p. (Estudos e pesquisas. Informação demográfica e socioeconômica, n. 37).

SROUR, R. H. Ética empresarial: a gestão da reputação. Rio de Janeiro: Campus, 2003.

TEIXEIRA, K. C da S. Discursos e práticas sobre a valorização da diversidade no âmbito empresarial: um estudo de caso. Gênero, Niterói, v.12, n.1, p. 81-108, 2011.

VIEIRA, L. Cidadania e globalização. 4. ed. Rio de Janeiro: Record, 2000.

WISE, L. R.; TSCHIRHART, M. Examining empirical evidence on diversity effects: how useful is diversity research for public-sector managers? Public Administration Review, v. 60, n. 5, p. 386-395, 2000.

\section{Cicilia Maria Krohling Peruzzo}

Professora visitante do Programa de Pós-Graduação em Comunicação da Universidade do Estado do Rio de Janeiro. Doutora em Ciências da Comunicação pela Universidade de São Paulo (ECA-USP). Fez pós-doutorado na Universidade Nacional Autônoma do México. Autora dos livros "Relações públicas no modo de produção capitalista”, “Comunicação nos movimentos populares” e “Televisão comunitária”. Organizadora de algumas coletâneas. Possui artigos publicados em diversas revistas científicas nacionais e internacionais. Ex-Coordenadora do GT Comunicación Popular, Comunitaria y Ciudadanía da ALAIC (Asociación Latinoamericana de Investigadores de la Comunicación), do GT Comunicação e Cidadania da Compós (Associação Brasileira de Programas de Pós-Graduação em Comunicação), e do GT Comunicação, Responsabilidade Social e Cidadania da Abrapcorp (Associação Brasileira de Pesquisadores de Comunicação Organizacional e Relações Públicas). Coordena o Núcleo de Estudos sobre Comunicação Comunitária e Local (Comuni). Bolsista de Produtividade em Pesquisa do CNPq (Conselho Nacional de Desenvolvimento Científico e Tecnológico).E-mail: kperuzzo@uol.com.br.

Recebido em: 25.02.2019

Aprovado em: 03.03.2021

Este artigo é publicado em acesso aberto (Open Access) sob a licença Creative Commons Attribution Non-Commercial (CC-BY-NC), que permite uso, distribuição e reprodução em qualquer meio, sem restrições, desde que sem fins comerciais e que o trabalho original seja corretamente citado.

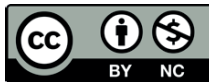

